\section{(跑) RMA}

Traducción Antropología Social

\title{
Los campesinos van a la playa
}

[Publicado originalmente como Les paysans à la plage en Actes de la Recherche en Sciences Sociales, vol. I, n², marzo 1975, pp. 21-24]

Patrick Champagne*

*Área Sociología del Institut national de la recherche agronomique (INRA) y Centre Européen de Sociologie et de Science Politique (CESSP - EHESS)

Traducción: Mariano Bussi** Revisión y corrección: Henry Boisrolin** **Licenciatura en Antropología, Facultad de Filosfía y Humanidades, Universidad Nacional de Córdoba

Todo se oponía en Saint Pierre-sur-Béhier ${ }^{1}$ a la práctica de irse de vacaciones, sobre todo entre los campesinos. La indistinción entre un espacio doméstico y otro de trabajo y las restricciones específicas de la actividad agrícola que supone una presencia constante -necesaria para la explotación en esta región de cría-, impedían la constitución de un tiempo y de un espacio que les sean propios a las ocupaciones y, otros, al ocio familiar. El conjunto de actividades de las familias campesinas, aisladas geográficamente y vinculadas entre ellas por las relaciones de cooperación, se encontraba establecido colectivamente por el grupo pueblerino, el que contaba con sus propios ritmos: ritmos estacionales del calendario agrario que -con sus trabajos- movilizaba durante el verano a los campesinos del pueblo, pero que también permitía momentos de "ocio" gracias a sus juegos para los hombres (juegos de cartas, juego de bolos, etc.), a sus lugares de reencuentro y de discusión para las mujeres (la plaza de la Iglesia, los comercios del poblado), a sus fiestas locales y a sus invitaciones habituales entre vecinos, las cuales expresaban y reforzaban la unidad de un grupo integrado dentro de un mismo espacio de residencia. Sólo abandonaban el pueblo, durante el verano, la pequeña burguesía local, partiendo, a veces junto con el sacerdote, a las propias residencias secundarias y

\footnotetext{
1 Esta nota, simple formalización de observaciones hechas a lo largo del trabajo de campo, es sólo un elemento de una investigación mucho más completa, realizada desde 1972 en un pueblo del norte del departamento de la Mayenne, cuyos primeros resultados fueron objeto de un artículo que próximamente aparecerá en esta misma revista. [Nota del editor: Aquí Champagne hace referencia a su extenso artículo "La restructuration de l'espace villageois", publicado en Actes de la Recherche en Sciences Sociales $n^{\circ} 3$, mayo de 1975, pp. 43-67. Hasta mediados de la década de 1980, esta revista publicó numerosos artículos dedicados al campesinado. Champagne, por ejemplo, fue autor de artículos como "La Féte au village", ARSS $\mathrm{n}^{\circ}$ 17-18, 1977, pp. 73-84 o "La reproduction de l'identité", ARSS n 65, 1986, pp. 41-64. Algunos de los autores con célebres artículos sobre campesinado publicados en Actes en esos años son Afrânio Garcia, Marie-France Garcia-Parpet, Sylvain Maresca y José Sergio Leite Lopes, por mencionar apenas autores publicados por nuestra RMA Agradecemos a Jerôme Bourdieu y al Consejo de Dirección de Actes de la Recherche en Sciences Sociales por la autorización para publicar la presente traducción].
}

algunos asalariados de la función pública que se habían instalado en el poblado, como el empleado de correos que regresaba con su familia o incluso el profesor que consagraba la mayor parte de sus jornadas no laborales a construir y acondicionar para su retiro una pequeña casa a orillas del mar.

Desde hace algunos años, la práctica de las vacaciones se difundió rápidamente entre la población no agrícola del pueblo. En lo sucesivo, el sacerdote y el profesor emprenden, por algunas semanas, viajes "turísticos"; unos comerciantes y artesanos cierran sus tiendas y parten por una parte del verano; los niños y los agricultores, quienes en otros tiempos ayudaban en los grandes trabajos del verano y retomaban la explotación familiar, son en la actualidad en su mayoría estudiantes o asalariados en una fábrica de las inmediaciones y parten, de a tres o de a cuatro en el automóvil de alguno de ellos, de camping. Se van, año a año, cada vez más lejos, y algunos de ellos incluso comienzan a pasarse a los países limítrofes (España, Suiza, etc.). Irse de vacaciones continúa siendo raro entre los campesinos, pero ya no se trata más para ellos de una práctica impensable; ellos denuncian que los "gajes del oficio" les impiden estar ausentes en sus granjas. Algunas familias, en su mayoría jóvenes parejas "modernas" de agricultores, comienzan a abandonar, por una semana o dos, su explotación cuando pueden confiársela a un pariente o a un vecino. No obstante, la salida dominical en automóvil a los lugares de vacaciones se ha generalizado rápidamente entre los campesinos y se ha convertido en un paseo banal durante el período estival. El domingo, el pueblo se vacía de sus habitantes: los jóvenes, por la mañana, se amontonan en los automóviles y van de un pueblo a otro, un poco al azar, en busca de distracciones; los campesinos parten en un día "de paseo" con sus hijos y a veces con sus ancianos padres. Como cada fin de semana, el profesor se va con su familia, que reside en un pueblo vecino. La misa del domingo a la mañana, que atraía a la mayoría de la población pueblerina, toma lugar ante un público disperso que no permanece demasiado tiempo en el pueblo: los campesinos no van más, o 
asisten a la misa del sábado a la noche, en la cabecera del cantón, para poder partir el domingo a la mañana. A la tarde, los cafés están desiertos. Solos, en la plaza, algunos artesanos añosos juegan a los bolos. Son todas señales de la transformación del modo de aglomeración de la población pueblerina y del repliegue sobre la familia nuclear que encuentra en la televisión y en el automóvil los instrumentos privilegiados de ocio doméstico utilizados para reforzar la integración familiar. El domingo tiende así a devenir, para los campesinos, en un día "familiar", o mejor dicho, en un tiempo vacante que demanda ser ocupado individualmente. La gente del pueblo -constata un campesino- se dispersa el domingo; ellos se fugan en familia; actualmente hacen lo que quieren y van a donde les plazca.

La observación etnográfica, un domingo del mes de agosto, de una playa de la costa normanda frecuentada a la vez por campesinos y por ciudadanos de vacaciones, permite percibir las contradicciones resultantes de la difusión de una práctica que simboliza tan perfectamente, para los campesinos, el modo de vida "urbano", y por la cual ellos pueden expresar su "modernidad" y su "dinamismo", es decir, su voluntad de acceder a las prácticas de los grupos con los cuales ellos tienden actualmente a compararse: Los otros parten -dice una joven agricultora- ¿por qué yo no? Trabajo como todo el mundo, quiero vivir como todo el mundo. Desde varias decenas de kilómetros a la redonda, grupos de jóvenes rurales y familias campesinas llegan, en automóvil, a reunirse en la costa cada domingo con los veraneantes urbanos. Sin duda esta playa era frecuentada desde hacía mucho tiempo por los campesinos; pero se trataba de salidas excepcionales que la mayoría de ellos no realizaba más de dos o tres veces en su vida. Llegaban en tren, en autobús, o incluso en algún transporte acoplado a pasar algunas horas en la playa para "ver el mar"; la mayor parte del día se invertía en el viaje en sí mismo. Se relacionaban con una burguesía, sobre todo rural, que pasaba gran parte del verano en sus cabañas construidas a lo largo de la costa. Hoy en día, los campesinos ya están allí desde la mañana, en medio de la multitud de veraneantes compuesta esencialmente por miembros de las clases populares y de las clases medias.

Para los campesinos, aún más que para los asalariados agrícolas o para los obreros, los gastos destinados a las vacaciones pertenecen a la categoría de gastos "superfluos", la preponderancia de éstos corresponde a las inversiones hechas para la explotación agrícola (cf. tablas 2 y 3). Como las clases populares, los campesinos más bien acampan en lugar de instalarse realmente en el espacio estival que, con sus campos deportivos (golf, tenis, etc.), sus salones de té o sus posadas "rústicas" con su costosa gastronomía, no está hecha "para ellos". Las clases populares consumen "especialidades locales" (moluscos fritos, crêpes bretonas, etc.) de bajo costo o almuerzan a menudo algún sándwich al costado de la ruta. Los campesinos, como en otros tiempos, prefieren llevar consigo sus provisiones; el automóvil les permite, por otra parte, llevar los materiales mínimos para picnic (sillas y mesas plegables) que ellos disponen, a la hora del almuerzo, justo al borde de la ruta, en las proximidades de su automóvil, del cual no se alejan. Estos picnics de familias campesinas y obreras instaladas unas al lado de las otras en un confort relativo, se oponen al mismo tiempo a aquellos de las clases medias sobreequipadas de materiales (heladera, anafe, casa rodante, etc.) que se instalan como "en sus casas" y muestran que ellos tienen "los medios", y a los "almuerzos de campo", practicados de manera ocasional por los miembros de las clases superiores, quienes se alejan de la ruta, en plena naturaleza y sin materiales, expresando así que se trata de una elección -el acercamiento a la naturaleza- y no de una necesidad económica. Los campesinos parecen más abiertamente preocupados que los miembros de las clases populares por los gastos que pueden llegar a generar en ese lugar donde todo es un llamado a gastar: inquietas miradas arrojadas sobre los tableros de precios, entradas dubitativas a los cafés, retos a los niños atraídos por los vendedores de golosinas y por los juguetes permanentemente expuestos a sus vistas por los comercios especializados, etc.

Los campesinos y los miembros de las clases populares se instalan directamente sobre la playa, única cosa que no les cuesta nada y en la que permanecen la jornada entera. Las familias delimitan con diversos objetos una porción del espacio que ellos no abandonarán más. Frecuentada anteriormente por las clases superiores y en la actualidad por las clases populares, esta playa no ofrece más que las instalaciones y actividades generalmente asociadas a las estaciones balnearias frecuentadas por los miembros de las clases medias que son sin duda los practicantes más "devotos": los clubes náuticos y los equipamientos deportivos están ausentes (a excepción de un minúsculo patio de recreación para los niños). Unos vestuarios estilo "1900", hoy poco utilizados, recuerdan la presencia de la burguesía. Las clases superiores urbanas evitan actualmente estas playas congestionadas por las otras clases sociales, vigiladas por salvavidas y la reglamentación en el baño. Sin embargo, la vieja burguesía local no ha renunciado totalmente: confortablemente instalada en las largas sillas alquiladas allí mismo, pasa así una hora o dos, el tiempo necesario para recorrer algunas de las páginas de una novela. Para lo miembros de las clases medias que se desplazan ampliamente por toda la región y practican el turismo "cultural" con sus visitas a museos y monumentos, la playa es solo un lugar entre otros en el que se realizan actividades específicas: ya sea para bañarse, para broncearse, para ocupar a los niños, para pescar, para navegar o incluso para no hacer nada. Los miembros de las clases populares y los jóvenes rurales ocupan sus tiempos de la misma manera, pero ellos practican estas actividades específicas con una menor intensidad y una "seriedad" inferior como es el caso, generalmente, de los practicantes ocasionales. Los campesinos, al contrario, parecen estar allí "como 
visitantes". Vienen a pasar el día, y esto solamente cinco o seis veces al año, no tienen la posibilidad de adquirir las técnicas de utilización de la playa que pueden aprenderse, al menos parcialmente, por familiarización, durante estadías prolongadas: vienen a menudo ya vestidos para la playa y se contentan con quitarse algún abrigo, una camisa o los zapatos; la mayoría de ellos no sabe nadar y van simplemente a mojarse los pies. Algunas viejas parejas de campesinos, revestidos de sus trajes y de sus vestidos gris oscuro de domingo, esos que se ponen para ir a la misa o para salir a la ciudad, pasan el tiempo recreando en este espacio sus ocupaciones habituales: sentados sobre una piedra en la orilla o sobre una silla plegable en medio de los estacionamientos, leen el periódico, tejen o arreglan prendas como si lo hiciesen en la entrada de sus casas. Numerosos son los campesinos que descansan, sentados en la playa, sin nada que hacer más allá de observar largas horas como espectadores involuntarios a los veraneantes; parecen esperar pacientemente el momento del regreso.

La heterogeneidad de los grupos sociales que se encuentran así reunidos en este lugar impone la comparación entre las clases y crea una situación propia a suscitar notablemente un sentimiento de vergüenza cultural por parte de los campesinos, poco familiarizados con las técnicas dominantes de utilización de la playa importadas por los miembros de las clases medias, y con las técnicas corporales a las que están estrechamente relacionadas. La vestimenta que utilizan, compuesta por elementos de la ropa de "todos los días" (camiseta), de ropa "para salir" (pantalón de vestir, gorra) y ropa "de veraneo" (short de color beige, pies descalzos, a veces en calcetines o incluso pies desnudos dentro de zapatos de vestir) contrastan con la que utilizan los citadinos que simbolizan diferencialmente según las clases sociales y las clases de edad el estatus de "vacacionista": camisa o remera, short blanco o traje de baño, sombrero de paja o gorra de marino, sandalias u ojotas, lentes de sol, etc. Los miembros de las clases superiores evitan la vestimenta de playa, demasiado "común", usando preferentemente estilos que manifiesten la práctica de actividades estivales a menudo costosas y por lo tanto selectivas, como el tenis o la náutica, por ejemplo. La ruptura con las limitaciones temporales de la vida cotidiana y, notablemente, con los horarios estrictos del trabajo asalariado que representa -para los miembros de las clases populares y de las clases medias- el momento de vacaciones, se expresa en sus gestos poco apresurados y en su paso arrastrado o pausado que marca, por la acumulación de signos de ostentación de desperdicio del tiempo, la búsqueda de la inacción por sí misma. El simbolismo corporal de estas clases traduce a otra, en ese lugar donde el cuerpo es objeto de espectáculo, la valorización de "la estética corporal" que supone el dominio en técnicas específicas del cuerpo adquiridas por la educación y cultivadas por la práctica de deportes, por el uso de productos de belleza y por la observación de regímenes alimenticios: ellos son alargados, descontracturados, un poco sobre el vientre, otro poco sobre la espalda para obtener un bronceado intenso y regular sobre la totalidad del cuerpo; los movimientos, rápidos y precisos o descompuestos en gestos simples efectuados sucesivamente en un ritmo constante, dando una impresión de "ligereza" y de "flexibilidad" específicas obtenidas por técnicas corporales que no deben prácticamente nada a aquellas de la vida cotidiana. La hexis corporal de los campesinos denuncia más directamente sus condiciones materiales y de trabajo: un paso pronunciadamente "pesado" por el uso permanente de botas y de zuecos, un bronceado desigual del cuerpo que deja ver las marcas de la ropa de trabajo, una fuerte corpulencia y unos brazos sueltos, ligeramente separados del cuerpo, destinados a dar una impresión de poder y de fuerza física, virtud tradicional definida según el sistema de valores campesinos del "buen trabajador", etc. Se sientan con las piernas estiradas y un poco separadas y con el cuerpo algo apoyado en un brazo, en búsqueda de una posición estable.

Los adolescentes, más escolarizados y más familiarizados con la práctica de deportes, se distinguen muy poco en sus comportamientos, de aquellos de las clases populares urbanas; apenas se reconoce, en los juegos brutales y en las demostraciones de poderío por parte de los varones, la persistencia de la valorización de la fuerza física. Es sin duda entre las mujeres, más preparadas que los hombres a estar atentas a todo lo que sea relevado de las "modas", en sentido amplio, que ejercen más fuertemente la dominación los modelos culturales impuestos y producidos por los miembros de las clases medias. La rigidez, la dubitación en los gestos, la torpeza de los movimientos denuncian el sentimiento de incomodidad que muchas de ellas experimentan al exponerse públicamente a las miradas, y también a los juicios de los "citadinos". Muchas se mantienen vestidas, y las que se desvisten lo hacen por etapas, con largas pausas, como retardando el momento en el que estarán en traje de baño. Ellas pasarán gran parte del día sentadas, discretas, casi inmóviles para no hacerse notar.

Último grupo social en acceder a la práctica de las vacaciones, el campesinado es sin duda también en el que se ve mejor el efecto de la imposición de la práctica. Salimos así porque sí, únicamente por salir -dice un campesino- es solo para decir que hemos salido. No disponiendo del capital cultural y económico necesario para la apropiación real de una práctica que ellos perciben como prestigiosa y que puede incrementar su propio prestigio, los campesinos son llevados a apropiársela, al menos nominalmente, adoptando las más inmediatas y exteriores características. Los lugares de vacaciones constituyen los lugares secundarios donde los campesinos entran en interacción con las otras clases sociales a las que deben afrontar solos, o si se quiere, en orden disperso, es decir, sin la posibilidad de la resistencia colectiva y activa que el grupo pueblerino como grupo real puede (o podía) oponer a los modos de comportamiento de las otras clases sociales. 


\begin{tabular}{lcccc}
\hline & $\begin{array}{c}\text { tasa de viajes por vacaciones } \\
\text { (en \%) }\end{array}$ & \multicolumn{2}{c}{$\begin{array}{c}\text { número de días por persona } \\
\text { vacacionista }\end{array}$} \\
\hline agricultores & 1961 & 1973 & 1961 & 1973 \\
- & $\underline{5,8}$ & 15,7 & $\underline{11,9}$ & $\underline{16,7}$ \\
asalariados agrícolas & $\underline{8,1}$ & & & \\
- & & & 21,8 & 27,4 \\
personal de servicio & 38,7 & 49,3 & 21,8 & 25,0 \\
obreros & 36,9 & 44,7 & 21,7 & 24,4 \\
artesanos y comerciantes & 37,4 & 56,7 & 23,8 & 28,5 \\
empleados & 57,2 & 60,3 & 27,7 & 31,0 \\
cargos intermedios & 73,0 & 77,9 & & 39,5 \\
cargos superiores y & & & 35,6 & 29,6 \\
profesiones liberales & 86,8 & 88,0 & 25,3 & \\
\hline conjunto & 37,5 & 49,2 & & \\
\hline
\end{tabular}

Tabla 1. Evolución de las tasas de viajes por vacaciones y del número de días por persona vacacionista según la categoría socio-profesional. Las estadísticas muestran que, a pesar del crecimiento del número de viajes por vacaciones, esta práctica continúa estando desigualmente distribuida entre los grupos sociales. Sin embargo, aún más que en el caso de los bienes materiales, la estadística, que es necesariamente construida a partir de taxonomías formales apoyándose en los índices más superficiales, tiende a estandarizar las prácticas que están en realidad marcadamente diferenciadas según los grupos y las clases. Este efecto de homogeneización de la estadística esta particularmente manifiesto en el caso de los campesinos como lo muestra la observación monográfica de sus prácticas reales de "vacaciones". (Fuentes: Etudes et conjoncture, supl. N4, 1965; Economie et statistique, 57, junio 1974, pp. 31-37).

\begin{tabular}{ll}
\hline menos de 6.000 francos & 11,6 \\
de 6.000 a menos de 10.000 & 21,0 \\
de 10.000 a menos de 15.000 & 32,1 \\
de 15.000 a menos de 20.000 & 42,2 \\
de 20.000 a menos de 30.000 & 55,4 \\
de 30.000 a menos de 50.000 & 68,8 \\
más de 50.000 & 81,1 \\
\hline conjunto & 44,6 \\
\hline
\end{tabular}

Tabla 2. Tasa de viajes por vacaciones (en \%) en relación a los ingresos declarados (1970). Sabemos que el costo ocasionado por el viaje por vacaciones a causa de los gastos específicos que él engendra y de las actividades particulares que él suscita lo hace diferencialmente accesible en relación a los ingresos de los que disponen los individuos. (Fuente: Données sociales, $1^{a}$ ed., 1973, INSEE, pp. 87-89)

\begin{tabular}{lr}
\hline en relación a las categorías socio-profesionales & \\
\hline agricultores & 521 \\
asalariados agrícolas & 695 \\
personal de servicio & 731 \\
obreros & 9.45 \\
artesanos y comerciantes & 1.369 \\
empleados & 1.116 \\
cargos intermedios & 1.539 \\
cargos superiores y profesiones liberales & 2.662 \\
\hline
\end{tabular}

Tabla 3. Gasto medio (en francos) por unidad familiar vacacionista. La jerarquía que se instaura entre las diferentes categorías de gastos posibles establece, diferencialmente en relación a los grupos sociales, las distinciones entre gastos prioritarios y secundarios, útiles o superfluos, permitidos o inalcanzables, etc. (Fuente: Etudes et conjonctures, 5, mayo 1966, pp. 3-59) 


\section{Algunas reflexiones al margen de «Los
campesinos van a la playa»}

selpe RMA

Patrick Champagne*

*Área Sociología del Institut national de la recherche agronomique (INRA) y Centre Européen de Sociologie et de Science Politique (CESSP - EHESS)

Antropología Social

Traducción: Mariano Bussi**
Revisión y corrección: Henry Boisrolin ${ }^{* *}$

**Licenciatura en Antropología, Facultad de Filosfía y Humanidades,

Universidad Nacional de Córdoba

La traducción al español y la nueva publicación de la corta nota de observación etnográfica titulada «Les paysans à la plage» ${ }^{1}$ que había redactado en 1975 invita a recordar tanto el contexto como las intenciones teóricas. La idea misma de esta nota se retrotrae a Pierre Bourdieu ya que fue él quien me la había sugerido durante una presentación de la investigación que yo estaba llevando a cabo en un medio rural. La idea de esta nota se inscribía dentro de los lineamientos de sus preocupaciones teóricas por entonces centradas en la noción de habitus, principalmente en su dimensión corporal. Él acababa de terminar su Esquisse d'une théorie de la pratique ${ }^{2}$ que se apoyaba en parte en su investigación sobre el celibato en Béarn. En esta investigación, que había dado lugar a un extenso artículo de $1962^{3}$, él había analizado el desplazamiento, en las pistas de baile de las danzas locales, del mercado matrimonial de los campesinos que, hasta muy recientemente, se limitaba a las familias espacial y socialmente próximas que, en función de su patrimonio territorial, se ocupaban de casar a sus hijos. Los jóvenes de las familias campesinas debían, de ahora en más, ir a buscar ellos mismos a su futura esposa. «Los campesinos van a la playa» hacía eco de la descripción etnográfica de uno de esos bailes ${ }^{4}$ donde Bourdieu explicaba, en síntesis, que los campesinos no conseguían casarse porque ellos no sabían danzar y se quedaban al borde de la pista de baile, su hexis corporal no era aquella que era convocada y ajustada en ese lugar dominado por una cultura y unas prácticas citadinas. La nota etnográfica sobre los campesinos en la playa se inscribía dentro de esta perspectiva teórica: al igual de lo que Bourdieu había

\footnotetext{
1 Actes de la recherche en sciences sociales, $n^{\circ} 2$, marzo 1975, pp. 21-24.

2 Ginebra, Droz, 1972 ; en formato de bolsillo (versión revisada y aumentada) : París, Editions du Seuil (col. Points Essais), 2000.

3 «Célibat et condition paysanne», Etudes rurales, 5-6, abrilseptiembre 1962, pp. 32-135 reproducido en Le bal des célibataires, París, Editions du Seuil, 2002. [Hay traducción al español: «Celibato y condición campesina». El baile de los solteros, Barcelona, Anagrama, 2004, pp. 17-129]

4 Ver esta descripción en la apertura de Le bal des célibataires, pp. 7-8. [En español, El baile de los solteros ob. cit., pp. 7-9].
}

analizado en Argelia, el desfasaje entre el habitus de un campesino tradicional y las estructuras económicas de tipo capitalista ${ }^{5}$, se trataba también de mostrar un caso de desfasaje entre las condiciones sociales de formación de los habitus y una situación convocante de otros habitus, aquí el desfasaje entre los usos sociales de la playa dominados por las clases sociales urbanas de vacaciones y una relación con el cuerpo estetizante y la relación con el cuerpo de campesinos fuertemente marcados por el trabajo de la tierra (manos deformadas y arruinadas, piel arrugada por el sol, bronceado parcial del cuerpo, etc.).

Aún más que una pista de baile, la playa desviste (en todos los sentidos del término) a los individuos e impone sus normas momentáneas sobre aquello que debe ser lo estético de los cuerpos desnudos que son exhibidos en ese lugar. Las dietas adelgazantes propuestas cada año en las revistas femeninas durante los meses que preceden a las vacaciones de verano explotan la ansiedad de los miembros de las clases sociales urbanas, y sobre todo de las jóvenes mujeres, al acercarse ese momento en donde se juega el valor de los individuos en el mercado sexual y matrimonial. El interés de la observación de los campesinos en la playa reside en parte en el hecho de que esta ansiedad era aquí particularmente fuerte y el principio de una verdadera vergüenza cultural perceptible y por lo tanto objetivamente pasible de ser captada en los comportamientos.

Lo que no estaba dicho en esta nota, y que amerita ser precisado aquí, es que la situación captada era excepcional en otro sentido. En efecto, la observación estaba enfocada sobre un momento que no estaba destinado a durar, un momento donde, a partir de las rápidas transformaciones de las estructuras sociales, el habitus de ciertos grupos sociales se encontraba provisoriamente desajustado en relación a las estructuras sociales. Hoy, en Francia, los campesinos en la playa no

\footnotetext{
${ }^{5}$ Ver Algérie 60, París, Editions de Minuit, 1977, principalmente pp. 83-114 [-hay traducción al español: Argelia 60, Buenos Aires, Siglo XXI, 2006, principalmente pp. 93-112] y Esquisses algériennes, París, Editions du Seuil, 2008, principalmente pp. 153-261.
} 
se distinguen en absoluto de los otros grupos sociales porque todos ellos han aprendido a nadar en el curso de su escolaridad y porque se han escolarizado en aquellas mismas técnicas del cuerpo que las de las clases sociales citadinas. Es decir que esta nota etnográfica observa un caso particular de la relación que se puede establecer entre los habitus y las estructuras objetivas.

Esta nota se inscribía igualmente dentro de la política editorial de la tan nueva revista que Pierre Bourdieu, en 1975, venía de fundar-Actes de la recherche en sciences sociales-y que quería romper con las normas académicas de las revistas existentes con sus artículos estándares redactados para los profesionales (es decir, los colegas). Bourdieu, que quería hacer una revista intelectual comprometida, se apoyaba sobre las ciencias sociales deseando diversificar tanto en sus objetos como en sus modos de tratamiento los informes de las investigaciones sociológicas con el fin de hacer accesibles los resultados a un público más grande que aquel compuesto por los sociólogos sin renunciar, sin embargo, al rigor del análisis científico ${ }^{6}$. "Los campesinos van a la playa» no habría podido, probablemente, haber sido publicado en una revista académica: esta nota etnográfica era demasiado corta y demasiado discreta teóricamente. Ahora bien, Bourdieu quería igualmente mostrar que era posible, por una descripción empírica precisa pero habitada por una intención teórica fuerte, hacer perceptible a los no especialistas conceptos muy abstractos de las ciencias sociales, en este caso, el de la dominación simbólica. Sin duda, no fue una casualidad si fueron numerosos aquellos (sociólogos y no sociólogos) que, en Francia y en otros lugares (Brasil, Portugal, Rusia, etc.), reconocieron situaciones parecidas en su país a aquella que era descrita en esta corta observación puntual hecha en una playa normanda en 1975, lo que atestiguaba que lo más empírico no es necesariamente lo menos teórico y que lo más monográfico no es lo menos generalizable.

\footnotetext{
${ }^{6}$ Es esta misma intención la que dará comienzo al libro La Misère du monde (Paris, Ed. du Seuil, 1993) que Bourdieu redactará con una decena de colaboradores. [Hay traducción al español: La miseria del mundo, Buenos Aires, Fondo de Cultura Económica, 1999].
}

El último punto que quisiera abordar a propósito de esta nota es el del vocabulario utilizado para describir, sin estigmatizarla, una población objetivamente estigmatizada. La escritura fue laboriosa y necesitó de muchas reescrituras, las primeras versiones del texto fueron redactadas de manera etnocéntrica a partir del punto de vista dominante: por ejemplo, el cuerpo de los campesinos era brutalmente calificado de "gordo» o de «regordete», lo que comportaba un juicio de valor implícitamente anexado por el observador. ¿Se debía, entonces, realizar una descripción objetivista limitándose a dar una estimación aproximativa del peso de aquellas mujeres sin comentarios? Pero esto conducía, en consecuencia, a perder la dimensión social de lo físico, el hecho de que los cuerpos son el objeto de juicios de valor, el «gordo» aquí puede ser percibido positivamente, allá como alguien «macizo», «robusto». La solución que fue adoptada consistió en conservar el vocabulario indígena para describir los cuerpos en aquel lugar pero volviendo sistemáticamente la atención (principalmente por la expresión "socialmente considerado como...») en que se trataba de vocabulario indígena tal como era pasible de ser captado aquí, es decir, de la percepción que los agentes sociales poseen de ellos mismos y de los otros en aquel lugar, las categorías de percepción pudiendo ser diferentes al interior de un grupo campesino.

Al momento de concluir este regreso sobre esta breve nota, quisiera haber convencido de que el interés que ella no ha cesado de suscitar reside sin duda, en gran parte, en la fuerte intención teórica de la que se encuentra investida, en el estado práctico y en el hecho de que conduce a presentar otra mirada, más comprensiva, sobre los comportamiento sociales. Un hijo de campesino que había hecho los estudios superiores y que devino maestro de conferencias en la universidad me había dicho, después de haber leído esta nota: «jes exactamente eso!», pareciendo redescubrir, paradojicamente, aquello que él ya sabía, pero que descifraba y juzgaba de otra manera, a partir de ese momento.

París, Mayo de 2012 